\title{
Invasion of cranial nerves by salivary cylindroma: four cases treated by radiotherapy
}

\author{
MICHAEL SWASH \\ From the Neurological Department, London Hospital, London
}

\begin{abstract}
SUMMARY Four cases of adenoid cystic carcinoma (cylindroma) of accessory salivary tissue are described, and the diagnostic difficulties experienced are emphasized. The tumour infiltrates cranial and other nerves and may invade the central nervous system by this route. It is highly malignant and may metastasize widely both by haematogenous and lymphatic pathways. The tumour is radiosensitive and it is suggested that the treatment of choice is radiotherapy combined, when possible, with surgical excision of the primary lesion. Metastases should be treated with radiotherapy since useful remission may occur.
\end{abstract}

Salivary adenocarcinomas may be subclassified according to their histological appearances and this is a valuable indication of prognosis (Ackerman, 1968). Adenoid cystic carcinoma, formerly termed salivary cylindroma on account of its characteristic growth pattern, forms one of the rarer, and despite its sometimes apparently well-differentiated appearance, one of the more malignant of these subgroups (Dockerty and Mayo, 1943). The tumour is usually thought of as arising from one or other of the major salivary glands and most of the reported cases fall into this category (Smith, Lane, and Rankow, 1965). However, adenoid cystic carcinoma may also arise in accessory salivary tissue and Harrison (1956) has drawn attention to the more malignant behaviour of the tumour in this situation. It is the purpose of this report to discuss the clinical features of four such cases, in two of whom diagnosis proved difficult because of the unusual presentation, and to stress the response to radiotherapy.

CASE 1

(W.G. LH 40159) In 1965 this 55 year old man noticed a small, hard gland in the right side of his neck and biopsy showed the node to be replaced by adenoid cystic carcinoma. There was no clinically evident primary lesion and no further tumour was found in a block dissection of the right side of the neck. Eighteen months later he complained of a tickling feeling in his throat, and at laryngoscopy the right vocal cord did not move and a mass was seen in the right piriform fossa. Widefield laryngectomy was performed and malignant 'cylindromatous' tumour was found in the piriform fossa (Fig. 1). Invasion of small veins by tumour cells was seen at the edge of the tumour. In 1967, six months before his death, he complained of persistent low backache and right-sided sciatica. In a few weeks he developed weakness and numbness of the right leg with faecal incontinence, and was readmitted.

On examination there was severe weakness of the right leg in an L5/S1 dermatomal distribution and the right ankle jerk was absent. Both plantar responses were flexor. There was sensory impairment in the L5-S5 dermatomes on the right side, and straight leg raising was limited by pain on both sides. The sacrum was tender to pressure but radiographs of the lumbar and sacral spine were normal. A lumbar myelogram, however, showed narrowing and irregularity of the Myodil column at the level of the body of the fifth lumbar vertebra with a posteriorly situated filling defect at this level. The cerebrospinal fluid contained $100 \mathrm{mg} / 100 \mathrm{ml}$. protein but no cells.

A laminectomy was performed (Mr. T. T. King) and tumour was found infiltrating the laminae of the upper sacral and lower lumbar vertebrae (Fig. 2). The cauda equina was compressed by extradural tumour at the level of the myelographic abnormality and the emerging roots were grey in colour and infiltrated by tumour. Postoperatively, he was treated with palliative radiotherapy $\left(3,500 r, \mathrm{Co}^{60}, 10\right.$ treatments in 14 days) but, although there was subsequent partial relief of pain, he gradually deteriorated, and died six weeks later with pulmonary metastases.

CASE 2

(A.N. LH 1457/59) In 1961 this 43 year old man noticed right frontal and maxillary headache and numbness and tingling in the right upper lip, and in December 1961 a bloody discharge appeared from the right nostril. Radiographs showed opacity of the sphenoid sinus with erosion of the floor of the sella turcica, but exploration 


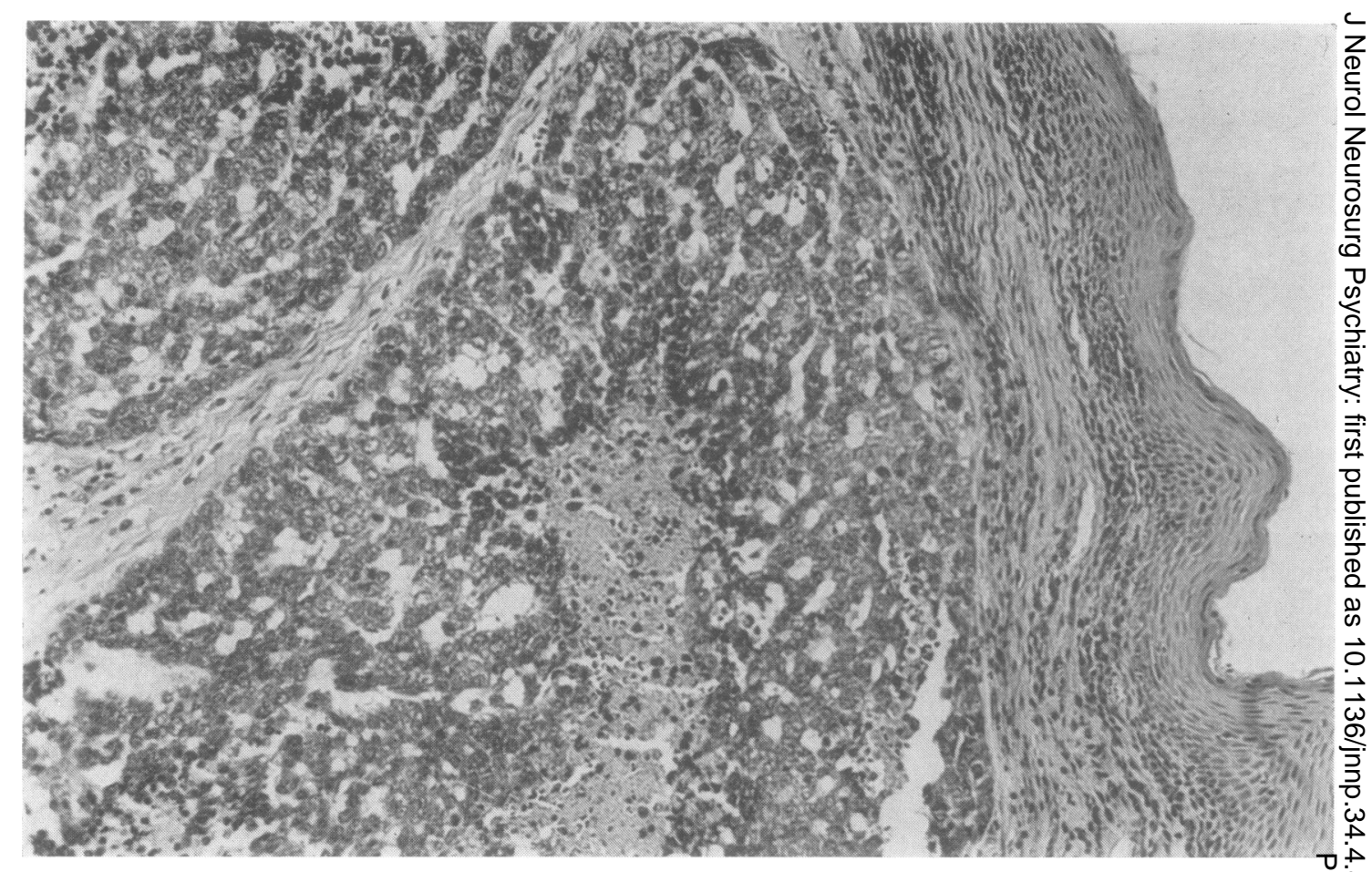

FIG. 1. Case 1. Cylindromatous tumour (adenoid cystic carcinoma) is present beneath intact mucosa in the pirifor fossa. $\times 150$.

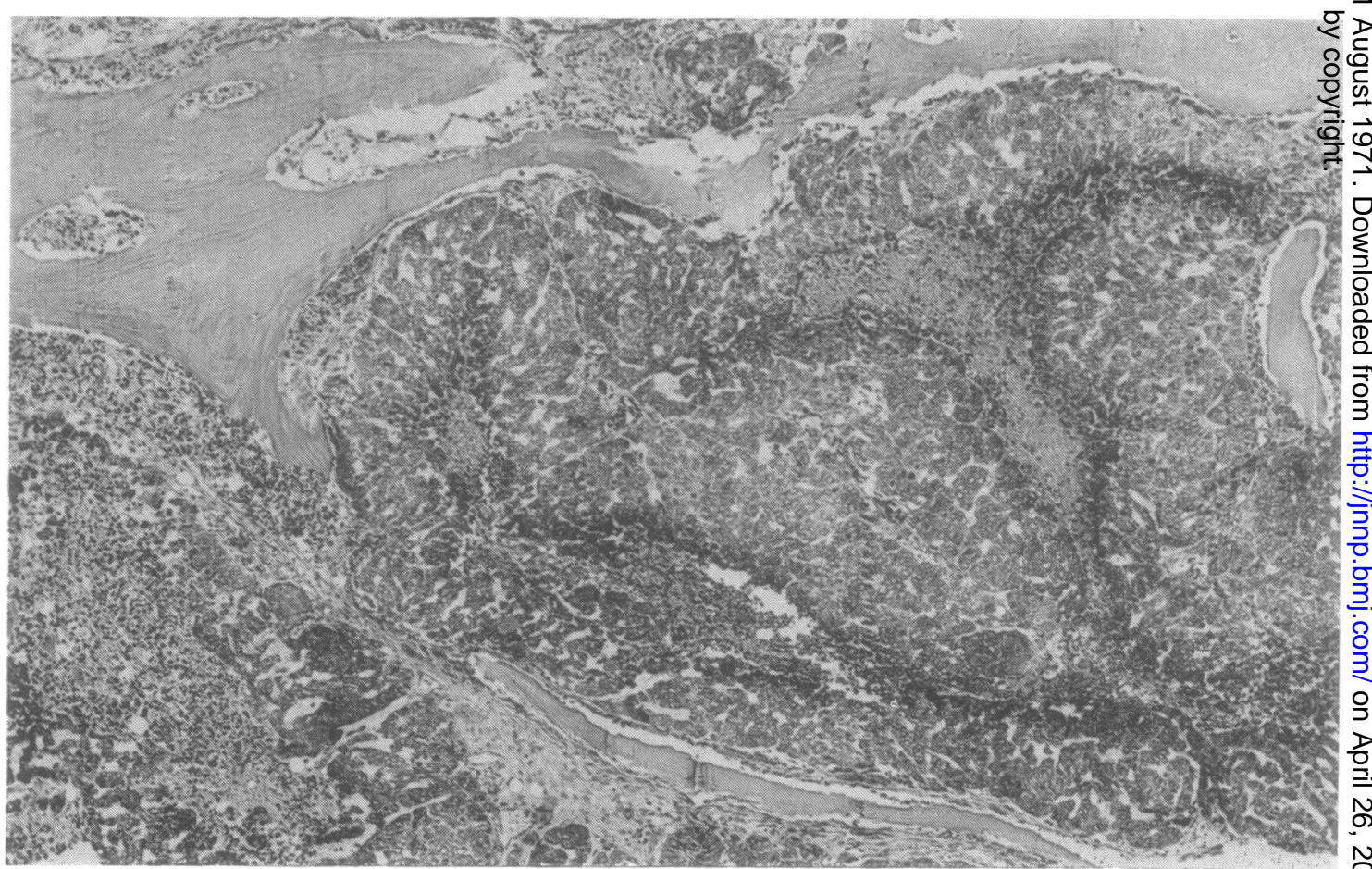

FIG. 2. Case 1. Laminectomy specimen. Infiltration of bone marrow by adenoid cystic carcinorna, without bony destruction. $\times 50$. 
and biopsy of this region was negative. In May 1962 he found difficulty in reading small print and developed obstruction of the right nostril. Right facial pain was severe and continuous. At that time the visual acuity was 6/36 left and 6/18 right (corrected), and there was a left temporal hemianopia. The left optic disc was pale and there was early papilloedema on the right. There was a right Horner's syndrome and mild right-sided proptosis. Skull radiographs now showed extensive destruction and opacity of the sphenoid sinus, the right maxillary antrum, and the right ethmoid sinus, and biopsy of the mass in the maxillary antrum showed a 'cylindromatous' type of salivary tumour. Radiotherapy was given $\left(4,500 r, \mathrm{Co}^{60}\right.$, 20 treatments in 29 days) but severe right-sided facial pain continued, and this was relieved only by extradural section of the right trigeminal sensory root (Mr. T. T. King). During the following 18 months, however, right facial pain returned and he developed bilateral anosmia, right facial weakness, right-sided palatal paralysis, and right-sided conductive deafness. Pulmonary metastases appeared and he died with pneumonia and a pleural effusion in February 1964, 18 months after the onset of the illness.

\section{CASE 3}

(S.P. LH 3323/57) In 1963 this man, then aged 47 years, noticed a persistent ache in his hard palate. Three years later a small palatal mass appeared and gradually enlarged, and in September 1967, after radiographic demonstration of local bony erosion, a biopsy showed an infiltrating 'cylindromatous' salivary tumour (Fig. 3). There were no metastases and the tumour regressed with radiotherapy $\left(6,000 \mathrm{r}, \mathrm{Co}^{60}, 20\right.$ treatments in 25 days), but in June 1968 he noticed numbness and a persistent aching pain in a small area above the right upper lip. Biopsies taken from the floor of the right maxillary sinus were normal, but by October 1968 the area of numbness had enlarged to involve the right cheek and tongue in addition to the right upper lip. At this time he began to complain of right frontal and temporal headache and of pain, localized deep to the right eye. In December 1968 he noticed diplopia on right lateral gaze and right-sided deafness. By March 1969 slight right-sided proptosis had developed and there was sensory loss in the distribution of the second division of the right trigeminal nerve, a right lateral rectus palsy, and right-sided conductive deafness. Skull radiographs showed a mass in the postnasal space and erosion of the base of the skull and he was treated with a course of radiotherapy directed to the base of the skull on the right side $\left(600 r, \mathrm{Co}^{60}, 25\right.$ treatments in 36 days), which relieved his headache, although the cranial nerve signs remained unchanged.

In July 1969 he complained of pain in both arms in a C6 dermatome distribution, and of a dull ache in the low cervical spine. On examination there was weakness of

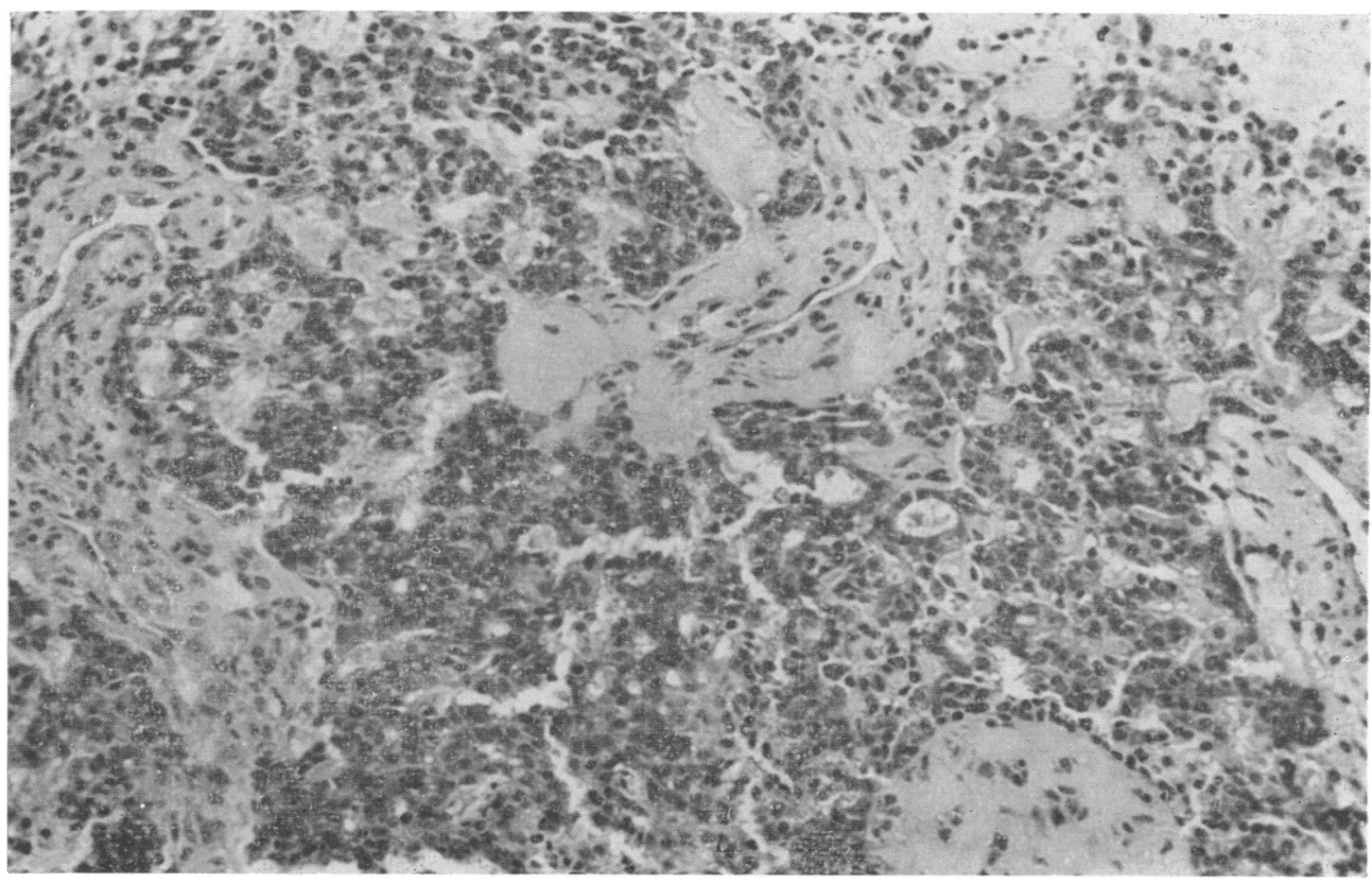

FIG. 3. Case 3. Biopsy of palatal mass. Note cylindromatous pattern of tumour growth. $\times 350$. 
extension of the right wrist and fingers with weakness and fasciculation of the right triceps muscle, and the right triceps jerk was absent. There was sensory impairment to pinprick and light touch in the right $\mathrm{C7}$ and $\mathrm{C} 8$ dermatomes. The right plantar response was extensor. Radiography of the cervical spine showed destruction of the body of the sixth cervical vertebra and the body of the fifth cervical vertebra was displaced forwards by $1 \mathrm{~cm}$ relative to that of the seventh cervical vertebra. There were lytic lesions in several other cervical vertebrae. He was treated with palliative radiotherapy to the cervical spine $\left(3,500 r, \mathrm{Co}^{60}, 10\right.$ treatments in 14 days) and there was considerable improvement in pain, weakness, and sensory loss, although the right plantar response remained extensor.

In the ensuing year he developed symptoms of recurrence of the tumour at its primary site, painful metastases in the thoracic spine, and then multiple lumbar root lesions due to metastases in the pelvis. On each occasion he was treated with palliative radiotherapy and his symptoms were relieved, but he died of pulmonary metastases in September 1970, seven years after he had first noticed a palatal swelling.

\section{CASE 4}

(W.R. LH 346144) In 1969 this 66 year old man was readmitted for investigation. He had first complained of weight loss and dysphagia - for which no cause had been found-in 1966, and in 1967 his voice had become hoarse. At that time he was found to have a right vocal cord palsy, a right palatal palsy with impaired palatal sensation, weakness and wasting of the right sternomastoid and upper part of right trapezius, and right-sided conductive deafness. Although it was thought likely on clinical grounds that he had a tumour of the glomus jugulare, extensive investigation, which included pneumoencephalography and jugular phlebography, was normal. In 1968 he noticed right facial weakness and a little later he was found to have sensory impairment in the distribution of the second division of the right trigeminal nerve. Right facial pain became severe and continuous and for six months he had a persistent, dull occipital headache.

On admission he was thin and anxious. There was rightsided conductive deafness, a right Horner's syndrome and palsies of the right fifth, seventh, ninth, tenth, eleventh, and twelfth cranial nerves. The left-sided cranial nerves and the fundi were normal and there were no signs in the limbs. Skull radiographs, with views of the jugular foramina and right internal and external carotid angiography, pneumoencephalography, and CSF examination were all within normal limits. The ESR was $14 \mathrm{~mm} / \mathrm{hr}$. (Westergren).

At posterior fossa exploration (Mr. T. T. King) a pale creamy layer of tumour was seen coating the external surface of the dura mater and infiltrating the suboccipital muscles. Tumour was also found on the inner surface of the dura mater surrounding and infiltrating the ninth, tenth and eleventh cranial nerves. These, and the right fifth nerve, were grey and atrophic, but no substantial mass of tumour was seen. Histological exam- ination of the tumour showed the characteristic features $\underset{D}{Z}$ of adenoid cystic carcinoma. Postoperatively he was treated with radiotherapy $\left(4,500 r, \mathrm{Co}^{60}, 20\right.$ treatments in 25 days) and this treatment relieved his facial pain, although the cranial nerve palsies remained unchanged. In the year since surgical exploration and radiotherapy ${ }_{0}$ there has been no change in his clinical state.

\section{DISCUSSION}

These four cases illustrate the malignant natural $\overrightarrow{\vec{C}}$ history characteristic of adenoid cystic carcinoma when the primary lesion arises in accessory salivary tissue (Harrison, 1956).

In case 1 diagnosis was established by biopsy of $\frac{\bar{D}}{\widetilde{D}}$ an enlarged cervical lymph node and in case 3 by $\varnothing$ biopsy of a palatal mass, but in the remaining two cases histological diagnosis could not be made $\vec{\circ}$ easily even when there were clear symptoms and signs of invasion of the cranial nerves. In case 2 symptoms $\vec{\omega}$ of nasopharyngeal tumour preceded the development? of cranial nerve palsies by several months but histological diagnosis could not be made at this stage. In case 3 cranial nerve palsies developed five $\stackrel{+}{+}$ years after apparently successful treatment of primary palatal lesion by radiotherapy alone and case 4 cranial nerve palsies were a puzzling presen 9 ing feature of the patient's illness. All the patien with cranial nerve palsies suffered severe pain in $\bar{q}$ trigeminal distribution and in one case this was co relieved only by trigeminal sensory root section. There was no characteristic pattern to the dis. tribution of cranial nerve palsies save that in cases they were unilateral. In case 4 the diagnosis was.established only by posterior fossa exploration and in this case the site of the primary growth remains unknown.

The differential diagnosis of patients presenting with progressive cranial nerve palsies includes $\stackrel{\square}{\varrho}$ chordomas, tumours of the glomus jugulare, naso- $\overrightarrow{\vec{P}}$ pharyngeal carcinomas and sarcomas, reticuloses, $\stackrel{\circ}{3}$ and tumours in the cerebellopontine angle. We have also observed plasmacytoma and chondrosarcoma of the base of the skull presenting similarly. The non-neoplastic causes of this syndrome have been discussed by Thrush and Small (1970) and will not be reviewed here. Chordomas may present with uni- 3 lateral cranial nerve palsies and usually the seventh to twelfth cranial nerves are involved. In $65 \%$ of a group of such cases described by Kamrin, Potanos, 0 and Pool (1964) a nasopharyngeal mass was present and in $30 \%$ of their series of 30 cases there were $\frac{7}{0}$ field defects with reduced visual acuity. Visual field defects are uncommon in patients with naso- $N$ pharyngeal carcinoma; however, case 2 of the $N$ patients reported above had a left temporal hemi- N anopia. Mawdsley (1968) found that $50 \%$ of a series 
of 216 patients with nasopharyngeal carcinoma presented with neurological symptoms and our cases of adenoid cystic carcinoma fall into this category, although they ran a more malignant course with earlier distant metastases. Tumours of the glomus jugulare usually cause deafness, vertigo, and local pain but in more advanced cases there are unilateral cranial nerve palsies and, more rarely, a bloody aural discharge (Henson, Crawford, and Cavanagh, 1953; Siekert, 1956). This diagnosis was suspected at first in case 4 and the correct diagnosis was not made until posterior fossa exploration was undertaken. Although the presence and location of bony erosion in the plain skull radiographs may suggest a histological diagnosis this must be confirmed by biopsy, and before this is attempted contrast studies may be necessary, as in case 4 , to exclude primary tumours of the cerebellopontine angle or intracranial extension of a primary extracranial tumour.

Hobaek (1949) has observed that ectopic salivary tumours occur in various sites in proportion to the amount of mucous glandular tissue normally present. Adenoid cystic carcinoma, however, arises relatively more commonly in accessory salivary tissue than in the major salivary glands, so that a higher proportion of accessory salivary tumours are likely to run a malignant course. In Ackerman's (1968) series of 563 salivary tumours adenoid cystic carcinoma was found in 12 of 39 tumours of accessory salivary tissue, but in only 20 of 478 parotid tumours and 11 of 56 sub-mandibular tumours.

Three of the patients described above developed cranial nerve palsies and it is likely that this was the result of infiltration of the perineural lymphatics of the involved nerves by tumour cells (Willis, 1952). Microscopically, adenoid cystic carcinoma commonly infiltrates nerve, muscle, fascia, and the perivascular and marrow spaces of bone (cases 1, 3, and 4) and its growth is not limited by tissue planes (Smith, Lane, and Rankow, 1965). The tumour infiltrates bone without altering its architectural pattern and so may not produce radiographic changes. This was so in case 1 (Fig. 2). Systemic metastases occurred in three of the four cases and there is clinical evidence that dissemination of the tumour occurred both by haematogenous and lymphatic pathways, in addition to infiltration of cranial nerves and of bone.

The malignancy of adenoid cystic carcinoma arising from accessory salivary tissue is clear from study of these four cases and this point has been made by others (Harrison, 1956; Ackerman, 1968; Glickman, 1968). These authors state that the tumour is usually radioresistant, but this is not borne out by our experience. When diagnosis has been established by biopsy of a primary lesion, radiotherapy alone may achieve prolonged remission, as in case 3 , but in patients presenting with cranial nerve palsies, or with enlarged cervical nodes, the primary lesion may not be discovered for many months and effective treatment can thus be delayed. Histological diagnosis was made late in the natural history of the disease in three of the four cases described and this may have influenced the generally poor response to treatment. In case 1 the primary laryngeal tumour was not discovered until 18 months after adenoid cystic carcinoma had been found in a cervical lymph node and this patient died with metastases a year after radical laryngectomy. Because the malignancy of the tumour was not at first appreciated he had not been given radiotherapy. Case 4 presented with cranial nerve palsies and the site of the primary tumour remains unknown. Diagnosis was very delayed in this case and this was partly because neuroradiological investigation did not demonstrate the lesion in the posterior fossa even when the clinical signs were advanced.

Smith et al. (1965), discussing a series of patients with adenoid cystic carcinoma arising mainly from parotid and submandibular glands, concluded that useful remission and, in a few cases, even cure could be obtained by wide surgical excision of the primary lesion, when this was possible, combined with radiotherapy given to both primary and secondary lesions. They noted that radiotherapy could produce useful remission of symptoms even at the second and third recurrences and this effect was striking in our cases. In case 3 local palliative radiotherapy produced remission even at the seventh course of treatment, and in all cases the pain of bony metastases was relieved by radiotherapy. It is because of this radiosensitivity that early histological diagnosis is important, although it must be recognized that it may be difficult, as in case 4, to localize the anatomical site of the lesion even when there are obvious and progressive unilateral cranial nerve palsies.

I would like to thank Dr. R. A. Henson, Dr. C. J. Earl, and Professor $H$. Urich for allowing me to report on patients under their care and for their helpful comments during the preparation of this paper.

\section{REFERENCES}

Ackerman, L. V. (1968). Surgical Pathology, p. 447, 4th edn. Mosby: St. Louis.

Dockerty, M. B., and Mayo, C. W. (1943). 'Cylindroma' (adenocarcinoma, cylindroma type); report of two cases with metastases. Surgery, 13, 416-422.

Glickman, I. (1968). The oral cavity, in Textbook of Pathology, chapter xx. Edited by S. L. Robbins. W. B. Saunders: Philadelphia and London.

Harrison, K. (1956). A study of ectopic mixed salivary tumours. Ann. roy. Coll. Surg. Engl., 18, 99-122. 
Henson, R. A., Crawford, J. V., and Cavanagh, J. B. (1953). Tumours of the glomus jugulare. J. Neurol Neurosurg. Psychiat., 16, 127-138.

Hobaek, A. (1949). Intraoral mucous- and salivary-gland mixed tumors. Acta. radiol. (Stockh.), 32, 229-247.

Kamrin, R. P., Potanos, J N., and Pool, J. L. (1964). An evaluation of the diagnosis and treatment of chordoma. J. Neurol. Neurosurg. Psychiat., 27, 157-165.

Mawdsley, C. (1968). Neurological aspects of the reticuloses and of nasopharyngeal tumours. In International Symposium, Some Aspects of Neurology, p. 85-98. Edited by R. F Robertson. Royal College of Physicians: Edinburgh.

Needles, W. (1937). Malignant tumors of the nasopharynx, with special reference to neurological complications.
Clinical study of thirty-five cases. J. nerv. ment. Dis., 86, 373-398.

Robbins, S. L. (1967). Pathology, p. 815, 3rd edn. Saunders: Philadelphia.

Siekert, R. G. (1956). Neurologic manifestations of tumors of the glomus jugulare, chemodectoma, non-chromaffin paraganglioma or carotid-body-like tumor. Arch. Neurol. Psychiat. (Chic.), 36, 1-13.

Smith, L. C., Lane, N., and Rankow, R. M. (1965). Cylin droma (adenoid cystic carcinoma). A report of fifty-eight cases. Amer. J. Surg., 110, 519-526.

Thrush, D. C., and Small, M. (1970). How benign is facial numbness? Lancet, 2, 851-853.

Willis, R. A. (1952). The Spread of Tumours in the Human Body. 2nd edn., p. 124. Butterworth: London.

\section{The June 1971 Issue THE JUNE 1971 ISSUE CONTAINS THE FOLLOWING PAPERS}

Levodopa's awakening effect on patients with Parkinsonism GAYLE G. MARSH, CHARLES M. MARKHAM, and ROBERT ANSEL

Comparison of benefit from L-dopa in Parkinsonism with increase of amine metabolites in the CSF R. B. GODWINAUSTEN, B. D. KANTAMANENI, and G. CURZON

Uptake and release of ${ }^{14} \mathrm{C}$-5-hydroxytryptamine by platelets in affective illness DAVID M. SHAW, DAVID A. MACSWEENEY, NORMAN WOOLCOCK, and A. B. BEVAN-JONES

Effects of initial conditions on the Hoffman reflex GERALD L. GOTTLIEB and GYAN C. AGARWAL

Hamstrings stretch reflex in human spasticity DAVID BURKE, J. D. GILLIES, and JAMES W. LANCE

The corneomandibular reflex ROBERT M. GORDON and MORRIS B. BENDER

Sensory conduction from digit to palm and from palm to wrist in the carpal tunnel syndrome FRITZ BUCHTHAL and ANNELISE ROSENFALCK

Peripheral neuropathy after disulfiram administration CHRISTOPHER GARDNER-THORPE and SIDNEY BENJAMIN

Clinical observations on sensory effects of trigeminal dorsal root section ADOLFO LEY AND JOSÉ MA. GUITART

Closed head trauma and aphasia KENNETH M. HEILMAN, ARTHUR SAFRAN, and NORMAN GESCHWIND

Late results of bulbar trigeminal tractotomy D. MOFFIE

Visually evoked responses in multiple sclerosis E. T. RICHEY, K. A. KOOI, and W. W. TOURTELLOTTE

Analysis of electrodermal evidence for a paramedullary afferent tract in patients with a transection of the thoracic spinal cord MARCUS J. FUHRER
Some observations on the fluttering midline echo in echoencephalography D. N. WHITE and C. O. JENKINS

Chemical epidural abscess: case report N. VIJAYAN and P. M. DREYFUS

Acute controlled hypotension and EEG in patients witto hypertension and cerebrovascular disease P. HARMSE J. KJÆRULFF, and E. SKINHØJ

Spontaneous canine hydrocephalus: cerebrospinal fluig dynamics A. SAHAR, G. M. HOCHWALD, W. J. KAY, and J. RANSOHOFF

Cerebral arachnoid cysts in children M. J. G. HARRIS Symptomatic cysts of the telencephalic choroid plex $\overrightarrow{9}$ CHARLES R. NEBLETT and JOSEPH W. ROBERTSON

Recognition and naming of object-drawings by men with focal brain wounds FREDA NEWCOMBE, R. C. OLDFIELD, G. G. RATCLIFF, and W. WINGFIELD

Fatal encephalopathy complicating lymphoid interstitial pneumonia MICHAEL JEFFERSON, D. RIDDOCH, and $\mathrm{w}$. $\mathbb{D}$ THOMAS SMITH

Histochemically demonstrable fibre abnormalities in $\frac{3}{3}$ normal skeletal muscle and in muscle from carriers of $\bar{T}$ Duchenne muscular dystrophy c. J. MORRIS and J. A. RAYBOULD

Sensitized lymphocytes in muscular dystrophy: evidence for a neural factor in pathogenesis E. A. CASPARY, $\mathbf{s}$. $\frac{0}{7}$ CURRIE, and E. J. FIELD

Pancreatic encephalopathy B. SHARF and E. BENTAL

Note on the value of Frenzel's glasses for the recognition and qualitative evaluation of spontaneous nystagmus H. H. TSCHANG and M. SPENCER HARRISON

Book reviews 